\title{
Effects of the Antiestrogens, MER-25 and CI 628, on Rat and Hamster Lordosis
}

\author{
L. P. MORIN, J. BRADLEY POWERS, and MARY WHITE \\ Psychology Department, University of California, Berkeley, \\ California 94720, and Neuroscience Laboratory, University \\ of Michigan, Ann Arbor, Michigan 48104
}

\begin{abstract}
Antiestrogens were used to test the hypothesis that estrogen exerts a "maintenance," as well as a "priming," effect on rat and hamster sexual receptivity as it apparently does for guinea pigs. MER-25 (75 or $150 \mathrm{mg} / \mathrm{kg}$ ) significantly reduced rat $L Q$ when given -2 hr or $8 \mathrm{hr}$ after $\mathrm{EB}$ injection. MER-25 given at $34 \mathrm{hr}$ ( $2 \mathrm{hr}$ prior to P) failed to diminish rat LQ. With hamsters, MER-25 in large doses $(750 \mathrm{mg} / \mathrm{kg}$ ) given either at $-2 \mathrm{hr}$ or $34 \mathrm{hr}$ reduced lordosis duration to $40 \%$ of controls, but this effect was confounded by severe illness among the MER-25 injected animals. Lower doses failed to block behavior, but still produced some toxicity. CI 628 (50 $\mathrm{mg} / \mathrm{kg}$ ) greatly reduced hamster lordosis duration and increased lordosis latency when given $0 \mathrm{hr}$, but not $34 \mathrm{hr}$, after $\mathrm{EB}$. The results are consistent with similar previous work on rats and do not support the concept of estrogen "maintenance" in either rats or hamsters.
\end{abstract}

Among ovariectomized rats, hamsters, and guinea pigs, lordosis can be induced by the sequential administration of estrogen and progesterone (Boling and Blandau, 1939; Frank and Fraps, 1945; Dempsey, Hertz, and Young, 1936). Several lines of evidence suggest that estrogen must be available for a number of hours before progesterone is administered in order that the animal be "primed" for a synergistic action of the facilitatory hormones. If the interval between the two hormones is too short, sexual behavior is absent or inadequate (Zucker, 1966; Quadagno, McCullough, and Langan, 1972; Eaton, Goy, and Resko, 1975; McEwen, Pfaff, Chaptal, and Luine, 1975). Administration of $17 \beta$-estradiol, a form which is presumably utilized more rapidly than its esterified analog, estradiol benzoate (EB) (Eaton et al., 1975; Feder, Siegel and Wade, 1974), can facilitate lordosis in conjunction with progesterone, but the intensity of such behavior is considerably less than that which is induced following equal doses of EB (Feder and Silver, 1974; Powers, 1975). Results from intracranial application of protein synthesis inhibitors also suggest that the critical time of estrogen priming for synergy with progester- 
one occurs within a few hours after estrogen treatment (Quadagno and Ho, 1975; Terkel, Shryne, and Gorski, 1973).

$\Lambda$ recent experiment suggests that an additional estrogen requirement, besides its priming action, may be necessary to facilitate normal lordosis in guinea pigs (Feder and Morin, 1974). Although the antiestrogen MER-25 given near the lime of EB injection diminished lordosis quality, anliestrogen provided at the time of progesterone treatment virtually abolished the subsequent appearance of sexual receptivity. The results suggested that following its initial "priming" effect, estrogen must subsequently remain available to exert a "maintenance" effect on receptive behavior. This second estrogen action might be viewed as an essential component of the mechanism by which progesterone is able to synergize with estrogen to facilitate lordosis.

If this is true, the maintenance effect of estrogen might be present only in those species dependent upon an estrogen-progesterone synergism for lordosis. In ovariectomized rats, sexual receptivity can be readily induced by appropriate doses of EB alone (Davidson, Rodgers, Smith, and Bloch, 1968). Because of this, an estrogen maintenance action may not be necessary for the facilitation of lordosis in rats and, consequently, antagonists of estrogen action administered after the estrogen priming period should not affect lordosis. This is consistent with a number of reports (Arai and Gorski, 1968; Whalen and Gorzalka, 1973; Quadagno and Ho, 1975; Terkel, Shryne, and Gorski, 1973; Meyerson and Lindstrom, 1968).

In the experiments reported here we reexamined the effects of MER-25 on receptive behavior in rats by attempting to disrupt both the estrogen priming and estrogen maintenance processes. In addition, we performed similar experiments with hamsters because in this rodent, as in guinea pigs, lordosis is difficult to induce with estrogen alone, without progesterone synergy. Thus, we expected estrogen maintenance effects would be evidenced by the ability of antiestrogen treatment to impair receptive behavior even when given after the estrogen priming period had ended.

\section{EXPERIMENT I}

\section{Method}

Laboratory bred femalc Sprague-Dawley rats weighing 180-200 g were ovariectomized under LA-thesia (Haver-Lockhart, Shawnee, Kansas; sodium pentobarbital and chloral hydrate; $0.25 \mathrm{ml} / 100 \mathrm{~g}$ body $\mathrm{vt}$ ). Animals received ad lib. food and water in individual cages under 14:10 LD conditions with lights off at 1800 . One week after surgery, all animals were given $10 \mu \mathrm{g} \mathrm{EB}$ followed 36-40 hr later by $0.5 \mathrm{mg}$ progesterone $(\mathrm{P})$. Both hormones were administered s.c. in oil. The second week after surgery, animals were randomly 
assigned to treatment groups and given a $36 \mathrm{hr}$ sequence of $10 \mu \mathrm{g} \mathrm{EB} / \mathrm{kg}$ and $0.5 \mathrm{mg}$ P. MER-25 (ethamoxy-triphetol) was suspended in oil with a magnetic stirrer in concentrations of $75 \mathrm{mg} / \mathrm{ml}$ and $150 \mathrm{mg} / \mathrm{ml}$ and injected ip in doses of either 75 or $150 \mathrm{mg} / \mathrm{kg}$ body wt at the times indicated in Fig. 1. Control females were injected with EB and P only.

Sexually experienced stud males were group housed in a room with lights off from 1000 to 2000 . Testing was conducted from 1400 to 1600 in a darkened room by placing a female with a male adapted for 2 to $5 \mathrm{~min}$ in a semicircular (1.5 ft radius), Plexiglas fronted arena lighted by one $7.5 \mathrm{~W}$ bulb. The male was allowed 10 correctly oriented mounts and the female was observed for the occurrence of lordosis. Lordosis intensity varied among animals, but the criterion for a positive response was elevation of the nose equal to or above a horizontal line through the ear opening while the female was mounted. The proportion of mounts eliciting positive lordosis responses times 100 (lordosis quotient $=$ LQ) was used as the measure of sexual receptivity.

\section{Results}

MER-25 given in $150 \mathrm{mg} / \mathrm{kg}$ or $75 \mathrm{mg} / \mathrm{kg}$ doses effectively reduccd mcan lordosis quotient when administered $2 \mathrm{hr}$ prior to $\mathrm{EB}$ priming (Fig. 1; $p<.002$ and .05 , respectively, vs controls; Mann-Whitney $U$ test, 2-tail). The $150 \mathrm{mg} / \mathrm{kg}$ dose was also effective when given $8 \mathrm{hr}$ after the EB injection ( $p<.05$, Mann-Whitney $U$ test, 2-tail; the $75 \mathrm{mg} / \mathrm{kg}$ dose was not tested). Neither dose of antiestrogen significantly depressed the LQ when given 24 or $34 \mathrm{hr}$ after EB treatment.

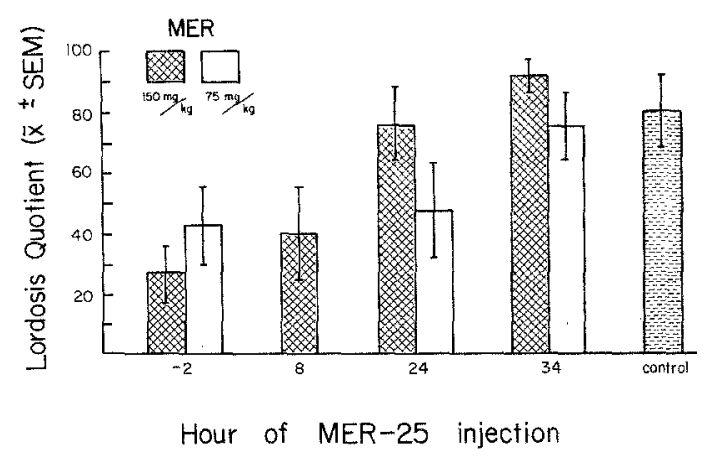

Fig. 1. Lordosis quotients of rats receiving a $36 \mathrm{hr} E B$ and $P$ sequence with MER-25 injections occurring at various times relative to the EB treatment. 


\section{EXPERIMENT II}

The sexual receptivity of individually housed ovariectomized hamsters (Con Olson, Madison, Wisconsin) was tested following EB and P treatments. These injections were combined with varying doses of MER-25 administered ip at different times during the $\mathrm{EB}$ and $\mathrm{P}$ injection sequence. Pilot experiments with approximately 24 hamsters made it apparent that this antiestrogen was quite toxic and generally unacceptable as a useful pharmacologic agent for behavioral studies in this species.

Relatively large doses of MER-25 were used initially; they were chosen so that the ratio of MER-25:EB doses would approximate the effective ratio in rats. This prompted our use of $750 \mathrm{mg} / \mathrm{kg}$. With subsequent groups, 525 $\mathrm{mg} / \mathrm{kg}$ or $300 \mathrm{mg} / \mathrm{kg}$ was administered; with all doses, MER-25 treatment was given either $2 \mathrm{hr}$ prior to EB injection or $2 \mathrm{hr}$ prior to P injection. MER-25 $(750 \mathrm{mg} / \mathrm{kg})$ given at either of the two injection times decreased the time over a 5 -min test period during which lordosis was displayed to approximately $40 \%$ of that exhibited by controls. However, with this dose the animals were sick for longer than 1 week on the average and three of 10 hamsters eventually died. Symptoms induced by MER-25 included diarrhea, excessive salivation, and some nose blecding. In general, these responses were more severe and lasted longer the higher the dose of MER-25 given. With $525 \mathrm{mg} \mathrm{kg}$, toxicity was again apparent but antiestrogenic effects on lordosis behavior were not evident. With $300 \mathrm{mg} / \mathrm{kg}$, toxic responses to the drug were minimal, and EB-P induced receptive behavior was not affected. In general, antiestrogen effects on lordosis could be observed only when the dose of MER-25 was sufficiently high to cause sickness in the treated hamsters. For this reason, another antiestrogen, CI 628 , was also used.

\section{EXPERIMENT III}

\section{Method}

Ovariectomized hamsters weighing approximately $100 \mathrm{~g}$ were housed individually under 12:12 LD conditions with lights off from 0900 to 2100 . During the first 2 weeks following ovariectomy, hamsters were given preliminary tests for hormonc-induced sexual receptivity once cach week; $50 \mu \mathrm{g}$ $\mathrm{EB} / \mathrm{kg}$ was injected s.c. at 2100 and $0.5 \mathrm{mg} P$ per animal was similarly administered $36 \mathrm{hr}$ later. Behavioral testing began at 1230 on the day of $P$ treatment. This involved scoring the total lordosis duration and the latency to the first display of lordosis during a 5-min test period. These tests were conducted in plastic boxes $(24 \times 24 \times 32 \mathrm{~cm})$ in which a sexually vigorous male had been adapted for $5 \mathrm{~min}$. A record was also kept of all mounts, 
intromissions and ejaculations achieved by the test male. The doses of EB and $\mathrm{P}$ and the interval between their injection remained the same for weeks 3 and 4 when the effects of antiestrogen treatments were tested.

Beginning on the third week, three groups were formed by matching for body weight and lordosis duration scores achieved on the two preliminary tests. Cl 628 (1-[2-(p-[-(p-methoxyphenyl)-b-nitrostyryl] phenoxy)ethyl] pyrrolidine, monocitrate) in $5 \%$ ethanol vehicle or the vehicle alone was injected s.c. to the different groups at one of three times with respect to $E B$ treatment. These times were $0 \mathrm{hr}$ (just prior to EB), $24 \mathrm{hr}$ ( $24 \mathrm{hr}$ after EB), and $34 \mathrm{hr}$ ( $2 \mathrm{hr}$ prior to $\mathrm{P}$ injection). On week 3, half the hamsters in each of the three groups were given $\mathrm{Cl} 628(50 \mathrm{mg} / \mathrm{kg}$ bw), and half were given vehicle injections $(5.0 \mathrm{ml} / \mathrm{kg}$ body wt). These treatments were reversed for week 4 . Behavioral testing was conducted as described above.

\section{Results}

The effects of CI 628 on receptivity in female hamsters are depicted in Fig. 2 and 3 . Antiestrogen compared to vehicle treatment at $0 \mathrm{hr}$ markedly suppressed lordosis duration ( 94 vs $274 \mathrm{sec}$, respectively; $p=.01$, Wilcoxon $T$ test). CI 628 injections given at $24 \mathrm{hr}$ also suppressed lordosis duration, but the absolute magnitude of this effect was attenuated (208 vs $267 \mathrm{sec} ; p=.02$ ). No significant differences were observed between antiestrogen and vehicle treatment at $34 \mathrm{hr}(274 \mathrm{vs} 263 \mathrm{sec})$.

This antiestrogenic effect of $\mathrm{CI} 628$ on lordosis duration was also reflected in an increased latency to the first display of lordosis among animals injected either at $0 \mathrm{hr}(163 \mathrm{vs} 14 \mathrm{sec})$ or at $24 \mathrm{hr}(69 \mathrm{vs} 39 \mathrm{sec} ; p=.01$ and

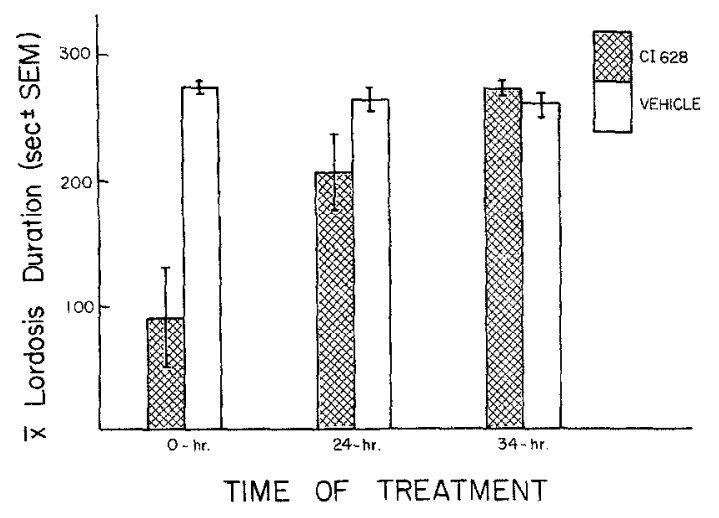

Fig. 2. Effects of $\mathrm{Cr} 628$ treatment at various times relative to EB and P injections on hamster lordosis duration. 


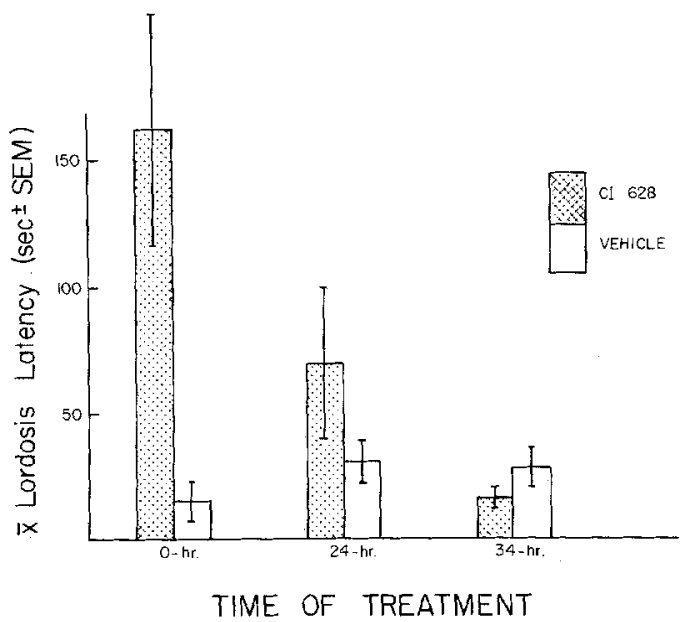

Fig. 3. Effects of $\mathrm{CI} 628$ at various times relative to $\mathrm{EB}$ and $\mathrm{P}$ injections on hamster latency to lordosis.

.05 , respectively). Treatment at $34 \mathrm{hr}$ had no effect on latency to lordosis (Fig. 3).

Although no systematic observation for symptoms of drug toxicity was made, Cl 628 caused no obvious debilitating side effects.

\section{DISCUSSION}

Antiestrogen administered near the time of EB injection significantly reduced the display of receptive behavior in both rats and hamsters. Comparable treatment $34 \mathrm{hr}$ following EB had no effect on lordosis. Although CI 628 given to hamsters at $24 \mathrm{hr}$ also reduced lordosis duration and increased latency, the magnitude of the effects were substantially less than after CI 628 at $0 \mathrm{hr}$. These results from rats and hamsters provide no evidence, in contrast to guinea pigs (Feder and Morin, 1974), that estradiol exerts a maintenance function on receptive behavior mechanisms which can be disrupted by competition with antiestrogen drugs.

In guinea pigs, antiestrogenic interference with estrogen maintenance functions is reflected not only in a reduced percentage of animals displaying lordosis, but also in a significantly shortened heat duration in those animals which do become receptive (Feder and Morin, 1974). Heat duration is a measure of the total period in hours over which lordosis can be elicited. This is to be distinguished from lordosis duration which measures the time in seconds over which a single lordosis response can be maintained. The 
dependence of heat duration on an estrogen maintenance process in guinea pigs is also indicated by the fact that heat duration can be lengthened if supplementary EB is provided at the time of progesterone administration (Joslyn and Feder, 1971). The testing procedures we used for assessing the receptive behavior of rats and hamsters did not include quantification of heat duration. For this reason our lack of evidence for estrogen maintenance functions in these species must be considered tentative. It is possible, for example, that the lordosis behavior of rats or hamsters injected with antiestrogen during the hypothesized estrogen maintenance period would differ from controls if tested at longer intervals after progesterone injection than we employed. The duration of the receptive period might have been shortened, but not detected by our single behavior test paradigm. Thus, although the present results do not support the idea that estrogen plays a maintenance role in rats and hamsters, this concept has not been fully tested.

Available evidence suggests that hamsters are less sensitive than rats to the behavioral and physiological effects of estrogen (Feder et al., 1974; Giannina, Butler, Popick, and Steinetz, 1971; Perry and Ferguson, 1974). This differential hormone sensitivity is reflected in a variety of ways. EB thresholds for the induction of lordosis differ by an order of magnitude between the two species (Powers and Valenstein, 1972; Feder et al., 1974). A dose of 150 $\mathrm{mg} / \mathrm{kg}$ MER-25 given prior to estrogen priming significantly reduced lordosis quotients in rats (Expt. I), whereas at least $750 \mathrm{mg} / \mathrm{kg}$ was necessary in hamsters to similarly affect receptivity and this effect was confounded by severe toxic reactions to the drug (Expt. II). In the rat, about $4 \mathrm{mg} / \mathrm{kg} \mathrm{CI} 628$ virtually abolished lordosis (Arai and Gorski, 1972; Powers, 1975), but 50 $\mathrm{mg} / \mathrm{kg}$ reduced hamster lordosis duration to only $34 \%$ of controls (Expt. III). These species differences in sensitivity to both estrogenic and antiestrogenic effects may be related to the fact that rat brain exhibits a much higher affinity for radioactively labeled estradiol than does the hamster brain (Feder et al., 1974).

It is uncertain to what extent altered hrain uptake and retention of estrogen is responsible for the antiestrogenic suppression of sexual receptivity (Whalen and Gorzalka, 1973). The differential effectiveness of MER-25 and CI 628 in both rats and hamsters is likewise not understood. However, a comparable difference in effectiveness of these two agents in blocking the uptake of estradiol into rat uterine tissue has been reported (Black and Kraay, 1973).

\section{ACKNOWLEDGMENTS}

This research was supported by NICHHD Grant HD-02982 to Dr. I. Zucker and by NIH Grant 1R01HD08281-01. L.P.M. was supported by an NIH postdoctoral fellowship. We thank Dr. Jerry R. Reel, Parke, Davis and Co., for supplying the CI 628 and Dr. Alfred Richardson, Jr., Merrell-National Laboratories, for the MER-25. 


\section{REFERENCES}

Arai, Y., and Gorski, R. A. (1968). Effect of antiestrogen on steroid induced sexual receptivity in ovariectomized rats. Physiol. Behav. 3, 351-353.

Black, L. J., and Kraay, R. J. (1973). Evaluation of two types of estrogen inhibition with regard to effects on uptake and binding of $\left[{ }^{3} \mathrm{H}\right]$-estradiol in the uterus. J. Ster. Biochem. 4, 467-475.

Boling, J. L., and Blandau, R. J. (1939). The estrogen-progesterone induction of mating responses in the spayed female rat. Endocrinology 25, 359-363.

Davidson, J. M., Rodgers, C. H., Smith, E. R., and Bloch, G. I. (1968). Stimulation of female sex behavior in adrenalectomized rats with estrogen alone. Endocrinology 82, 193-195.

Dempsey, E. W., Hertz, R., and Young, W. C. (1936). The experimental induction of oestrus (sexual receptivity) in the normal and ovariectomized guinea pig. Amer. $J$. Physiol. 116, 201-209.

Eaton, G. G., Goy, R. W., and Resko, J. A. (1975). Brain uptake and metabolism of estradiol benzoate and estrous behavior in ovariectomized guinea pigs. Horm. Behav. 6, 81-97.

Feder, H. H., and Morin, L. P. (1974). Suppression of lordosis in guinea pigs by ethamoxy-triphetol (MER-25) given at long intervals (34-46 hr) after estradiol benzoate treatment. Horm. Behav. 5, 63-71.

Feder, H. H., and Silver, R. A. (1974). Activation of lordosis in ovariectomized guinea pigs by free and esterified forms of estrone, estradiol-17 $\beta$ and estriol. Physiol. Behav. 13, 251-255.

Feder, H. H., Siegel, H., and Wade, G. N. (1974). Uptake of $\left[6,7-{ }^{3} \mathrm{H}\right]$ estradiol-17 $\beta$ in ovariectomized rats, guinea pigs and hamsters: Correlation with species differences in behavioral responsiveness to estradiol. Brain Res. 71, 93-103.

Frank, A. H., and Fraps, R. M. (1945). Induction of estrus in the ovariectomized golden hamster. Endocrinology 37, 357-361.

Giannina, T., Butler, M., Popick, M., and Steinetz, B. (1971). Comparative effects of some steroidal and nonsteroidal antifertility agents in rats and hamsters. Contraception 3, 347-359.

Joslyn, W. D., and Feder, H. H. (1971). Facilitatory and inhibitory effects of supplementary estradiol benzoate given to ovariectomized, estrogen-primed guinea pigs. Horm. Behav. 2, 307-314.

McEwen, B. S., Pfaff, D. W., Chaptal, C., and Luine, V. J. (1975). Brain cell nuclear retention of ${ }^{3}$ Hestradiol doses able to promote lordosis: Temporal and regional aspects. Brain Res. 86, 155.

Meyerson, B. J., and Lindstrom, L. (1968). Effect of an oestrogen antagonist ethamoxytriphetol (MER-25) on oestrous behaviour in rats. Acta Endocrinol. 59, 41-48.

Perry, K. W., and Ferguson, E. R. (1974). Uptake of oestradiol by rat and hamster uteri in vitro: Effects of ethynyl oestradiol and an anti-oestrogen. J. Reprod. Fert. 37, 113-116.

Powers, J. B. (1975). Anti-estrogenic suppression of the lordosis response in female rats. Horm. Behav. 6, 379-392.

Quadagno, D. M., and Ho, G. K. (1975). The reversible inhibition of steroid-induced sexual behavior by intracranial cycloheximide. Horm. Behav. 6, 19-26.

Quadagno, D. M., McCullough, J., and Langan, R. (1972). The effect of varying amounts of exogenous estradiol benzoate on estrous behavior in the rat. Horm. Behav. 3, 175-179. 
Terkel, A. S., Shryne, J., and Gorski, R. A. (1973). Inhibition of estrogen facilitation of sexual behavior by the intracerebral infusion of actinomycin D. Horm. Behav. 4, 377-386.

Whalen, R. E., and Gorzalka, B. B. (1973). Effects of an estrogen antagonist on behavior and on estrogen retention in neural and peripheral target tissues. Physiol. Behav. $10,35-40$.

Zucker, I. (1966). Facilitatory and inhibitory effects of progesterone on sexual responses of spayed guinea pigs. J. Comp. Physiol. Psychol, 62, 376-381. 